\title{
Using Second-Order Factor Analysis in Examining Multiple Problems of Clients
}

\author{
Cathy King Pike, Walter W. Hudson, Douglas L. Murphy and \\ Eloise Rathbone McCuan
}

Data from veterans of the Persian Gulf engagement were studied to assess the potential of second-order factor analysis in examining, interpreting, and directing person-environment interventions with an array of different but related individual and environmental problems. Participants of the study were 1,532 veterans of the Persian Gulf engagement who were eligible for social services provided by the Veterans Administration. The results provided support for the use of second-order factors in examining client data and provided information about the relationships among clinically significant problems. Further research on the second-order factors of multidimensional instruments that are used in social work to measure client progress can yield information about how client populations differ and provide direction in selecting interventions that are congruent with social work's person-environment focus.

Factor analysis is used often in developing instruments designed to measure client problems, aptitudes, or attitudes. Researchers use factor analysis to examine the items of their instruments and provide information about the content and construct validity of a new instrument. This is done by examining the item inter-correlations and determining the extent to which items cluster together along those factor structures that the researcher had hypothesized when developing the instrument. Traditional research on instrument development has focused on primary scale factors, that is, examining only the inter-correlations of items in scales. This approach ignores the possibility that various scales may be correlated, in addition to those correlations that were found among the items. Moderate intercorrelations among scales of a multidimensional instrument are common and suggest that scales can be reduced further and explained more concisely by their underlying constructs (Gorsuch, 1983). These scale correlations, called higherorder factors, define broader constructs that encompass more than one primary factor. Recent psychometric studies have begun to examine the presence of higher-order factors to identify general constructs for several scales measuring various aspects of a multidimensional construct. Most of the recent work has focused on examining higher-order factors of intelligence and ability tests in education (Bachelor, 1986, 1989; Bachelor \& Bachelor, 1989; Bachelor \& Michael, 1991; Bachelor, Michael, \& Kim, 1994; Blaha \& Mandes, 1993; Blaha, Mandes, \& Swisher, 1987; Blaha \& Wallbrown, 1982; C-Y Chen \& Michael, 1993; S. A. Chen \& Michael, 1993; Ulosevich, Michael, \& Bachelor, 1991; Wallbrown, Elliott, McLoughlin, \& Blaha, 1984). Only a few studies have examined higher-order factors for multidimensional personality and attitudinal measures (Tanaka \& Huba, 1984; Wilson, Sibanda, Sibanda, \& Wilson, 1989).

The most common rationale for undertaking studies of higher-order factor analysis of instruments has been to determine whether a more parsimonious explanation of the primary 
factor structures of instruments can be obtained, although some investigations (C-Y Chen \& Michael, 1993; S. A. Chen \& Michael, 1993; Michael \& Bachelor, 1992) have used higher-order factor analysis as a means of empirically examining the validity of the hierarchical theoretical constructs of intelligence developed by Guilford (1959) and Vernon (1950). Two studies have examined the higher-order factor structure of intelligence for atypical samples as compared to those found for the normative samples used in developing intelligence tests (Blaha et al., 1987; Blaha \& Mandes, 1993). One study used higher-order factor analysis to determine the crosscultural validity of personality measures and constructs (Wilson et al., 1989).

Higher-order factor studies can be used in social work to describe the general needs of client populations and to develop knowledge about those populations served by social work. Client functioning is often measured by instruments containing a variety of scales that assess personal, environmental, and social functioning. The use of second-order factors can explain general areas of individual, environmental, and social functioning more concisely than lengthy descriptions of numerous primary factor scores. Individual practitioners can make use of both first-order and second-order factors in developing interventions with clients. Clients having multiple, clinically significant problems present challenges to social workers in assessing and selecting target problems for interventions (Hepworth \& Larsen, 1993; Sheafor, Horejsi, \& Horejsi, 1994). Although multidimensional assessment tools aid in the selection of target problems, clients having a variety of clinically significant problems can pose difficulties for social workers in interpreting how related but different problems should be addressed. Social workers who intervene with multiproblem families or individuals need a means of (a) improving their understanding of how client problems are related, (b) assessing client progress over several related areas of functioning, and (c) adequately collapsing complex data to reflect a personenvironment focus.

This study reports the use of second-order factor analysis as a tool for examining an array of client data from a multidimensional tool (Gorsuch, 1983). The Multi-Problem Screening Inventory (MPSI) measures 27 areas of personal and social functioning and contains a total of 334 items. ${ }^{1}$ Prior examination of the MPSI provided reasonable confirmation of the a priori primary factors (Hudson, 1990; Hudson \& McMurtry, 1997). The purpose of this study was to determine whether higher-order factors could explain, with conceptual clarity and more concisely, the smaller number of general constructs that encompass the 27 primary scales.

\section{Methods}

Participants of this study were 1,532 veterans of the Persian Gulf engagement who were eligible for social services provided by the Veterans Administration (VA) through the Persian Gulf Family Service Program. Most of the participants were male $(\mathrm{N}=1,279,84 \%)$, and nonHispanic Whites ( $\mathrm{N}=1,287,91 \%)$. Forty-nine percent $(\mathrm{N}=757)$ were either married or living with a significant other. Examination of the means of the MPSI's 27 primary scales indicated clinically significant problems in a number of areas of personal and social functioning.

\footnotetext{
${ }^{1}$ Copies of the MPSI can be obtained from the WALMYR Pulishing Co., POB 6229, Tallahassee, FL 32314-6229.
} 
Internal consistency reliability coefficients and standard errors of measurement were computed for the 27 primary scales of the MPSI used with this sample. Cronbach's alpha was used in these analyses of internal consistency reliability. Missing values for all analyses in the study were deleted pair-wise. This method of handling missing data was selected to prevent the loss of data when scales measuring constructs not relevant to clients' situations were omitted by clinicians, for example, the Child Problems scale for a client having no children.

Before examining the second-order factor structure of the MPSI, a Multiple Group Method factor analysis was computed to generate the primary factors of the MPSI. The primary factors from this analysis were then used to compute a second-order factor analysis.

A second-order principal components factor analysis of the 27 scales in the MPSI was computed, using SAS (SAS Institute, 1989). Cattell's Scree test, an initial indication of the number of factors in an instrument, was used to assess the number of second-order factors present in the data (Cattell, 1966; Cattell \& Vogelman, 1977; Gorsuch, 1983). The Procrustean rotation of the Promax procedure was used to interpret the factor structure (Nunnally \& Bernstein, 1994). The Procrustean rotation allows researchers to evaluate the extent of correlations among the items or scales of a factor analysis.

Second-order maximum-likelihood factor analyses also were computed for this data. Secondorder maximum-likelihood factor analyses provide a test of the extent to which statistically significant second-order factors are present and assist researchers in comparing and identifying the best conceptual number and composition of factors. Although maximum-likelihood factor analysis is used as a confirmatory method, it is used here for exploratory purposes similar to those used by Tanaka and Huba (1984).

\section{Results}

\section{Internal Consistency Reliability}

The original validation research for the MPSI was based on a much smaller sample of subjects who also tended to be somewhat homogeneous in their responses. Homogeneity of responses can have a modest or even pronounced effect in attenuating estimates ofreliability (Nunnally \& Bernstein, 1994). Despite the relatively large reliability estimates obtained in the initial study, it was suspected that several were attenuated in magnitude by the response homogeneity of that sample. Reliability estimates and standard errors of measurement were computed for the 27 primary factors of the MPSI. The results are shown in Table 1. Examination of the results shows that 21 of the 27 scales in this sample have internal consistency reliability coefficients of .90 or better. Of the remaining six scales, five have coefficient alphas of .80 or better, and the sixth has a coefficient alpha of .79. These findings, combined with the very small values of the standard errors of measurement, show that the MPSI scales are excellent to superior in terms of their measurement error characteristics and are appropriate for use in practice-related decision making, where high reliability is particularly important. 


\section{Second-Order Factor Analyses}

A second-order factors principal components analysis, with a Promax rotation, was computed on the 27 primary scales identified by the multiple group factor analysis. The Scree plot indicated the presence of three second order factors. A three-factor model was specified. The 27 scales of the MPSI were explained by three factors, which were labeled (a) Individual Dysfunction, (b) Family and Environmental Problems, and (c) Partner Relationship Problems. Table 2 contains the factor loadings (correlations) for the second-order factors that were derived from the a priori primary factors. Table 3 contains the pattern loadings (standardized regression coefficients) for the second-order factors. Factor 1 (Individual Dysfunction) included 14 of the 27 scales and was composed entirely of problems relating to individual functioning, for example, depression, personal stress, aggression, and phobias. Factor 2 (Family and Environmental Problems) included problems with one's child, mother, father, friends, neighbors, school, work, and work associates. Because the participants were all adults, most of the familial problems measured by the scales in this factor referred to families of origin and can be viewed as environmentally related. Factor 3 (Partner Relationship Problems) contained four scales that measured partner relationship problems, that is, sexual discord, nonphysical abuse, physical abuse, and problems of the partner relationship. The Alcohol Abuse and Drug Abuse scales loaded most heavily on the Individual Functioning factor (Factor 1) and almost as heavily on the Partner Relationship Problems factor (Factor 3). Because substance abuse affects partner relationships almost as much as it involves individual problems, this is not a surprising finding. The three factors accounted for $50 \%$ of the variance of the sample and were divided as follows: Factor 1, .37; Factor 2, .08; and Factor 3, .06.

Maximum-likelihood factor analyses were computed to test the research hypothesis that the MPSI contained statistically significant second-order factors and to identify and compare the number and compositions of factor models. The initial analysis was a three-factor, second-order solution and resulted in a significant chi-square $(2,423.25$, df: $351, p=.0001)$ for the test of the research hypothesis that at least one common factor existed among the primary factors. A second chi-square test evaluated the null hypothesis that a three-factor solution was sufficient also had a significant value of $533.161(\mathrm{df}=273, \mathrm{P}=.0001)$. This finding indicated that a model with a greater number of factors may have been more appropriate for the data. The weighted, reduced correlation matrix accounted for virtually all of the variance in the data. Factors 1, 2, and 3 contained the following variances, respectively: $77 \%, 18 \%$, and $5 \%$. The three factors were congruent with the principal components analysis with respect to the factor labels that described the scales comprising each factor, and the scales loaded exactly for all but two of the variables.

A second maximum-likelihood factor analysis was computed for a four-factor second-order solution. The chi-square test of the null hypothesis that 4 factors were sufficient yielded a significant value of 7,690.87 $(\mathrm{d} /=351, \mathrm{p}=.0001)$. However, the Akaike's AIC and Schwarz's Bayesian criterion were higher for this model than for the three-factor solution. The Akaike's AIC and Schwarz's Bayesian criterion evaluate the model's parameter fit, and the increase in scores suggested that the three-factor solution was a better model. In addition, the fourth factor of this model contained only two scales (Drug Use and Physical Abuse) and accounted for less than $5 \%$ of the total variance, which indicates the possibility of correlated measurement errors among these two scales. 
The principal components and the maximum-likelihood second-order factor structures were compared with respect to conceptual clarity. The factor structures (correlations) for the principal components and three-factor maximum- likelihood analyses differed only for two scales, Child Problems and Friend Problems. The Child Problems scale loaded most strongly on the Familial and Environmental Problems factor (Factor 2) for the principal components analysis, whereas the maximum-likelihood analysis placed this scale with the Partner Relationship Problems factor (Factor 3). The Friend Problems scale loaded most heavily on Factor 2 (Familial and Environmental Problems) in the principal components analysis, whereas this scale loaded most heavily on Individual Dysfunction (Factor 1) of the maximum-likelihood solution. The fourfactor maximum-likelihood model agreed with the principal components solution for both the Friend Problems and Child Problems scales, although it placed the Drug Abuse and Physical Abuse scales in a fourth and separate factor. From a conceptual standpoint, the principal components three-factor second-order model is more clear than the three-factor maximumlikelihood model. In addition, the four-factor maximum-likelihood solution yielded less desirable results in the estimates of parameter fit.

\section{Discussion and application to social work practice}

The results from this study support the research hypothesis that second-order factors can be used to describe general constructs that encompass the 27 primary factors of the MPSI more concisely than referring to each of the 27 scales as separate constructs. However, it is important to remember two limitations of factor analysis. First, factor analysis does not yield results at the individual level. An individual's scale scores when compared to the factor structures can only be used to generate clinical hypotheses about a given client's constellation of problems. Second, higher-order factor structures for structure-of-intelligence have differed for atypical individuals when compared to normative samples (Blaha et al., 1987; Blaha \& Mandes, 1993). It is reasonable to conclude from those findings that factor structures can also differ among various client populations in social work. This study was based on data from veterans of the Persian Gulf engagement who were treated in 23 VA medical centers. Although inferences about the results of the second-order factor structures to those medical centers are probably reasonable, the factor structures of the MPSI identified in this study may not apply to other VA medical centers or to different client populations.

When further research is completed, social work administrators and practitioners can use the results from higher-order factor analyses in practical ways to meet clients' needs. Administrators can develop information through second-order factor analyses of multidimensional instruments used in their agencies about the general problems that are common among their agency's clientele. This information can then be used to plan in-service training for the types and duration of interventions for clients served by an agency. Practice knowledge for specific client populations can be generated from second-order factor analyses. For instance, if a random number of veterans from different "limited military conflicts" are studied, useful knowledge can be developed about how best to intervene with individuals having experienced limited military conflicts. The veterans in this study had clinically significant means at the second-order level for two factors: Individual Dysfunction, and Familial and Environmental Problems. Practitioners 
reasonably may focus on interpersonal and communication strategies for the problems relating to families and the environment. Veterans had the highest scale means in the Individual Dysfunction factor for scales measuring depression, self-esteem, personal stress, and confused thinking. Of these, depression, personal stress, and confused thinking may point toward a diagnosis of post-traumatic stress disorder. The Confused Thinking scale is particularly suggestive of this diagnosis, because it refers to problems in thinking straight and to problems of one's mind playing tricks. Interventions with these veterans would include those found to have been effective with post-traumatic stress disorder.

Because interventions in social work that are geared toward one presenting problem often affect related areas of functioning, measurement of progress for these clients would involve assessing progress across the clinically significant primary scales that comprise a given second-order factor. A common mistake made by social workers when measuring client progress has been to limit measurements to one or two presenting problems. When clients show no improvement in the areas measured, social workers can be misled about progress made, but not measured, in related areas. Measurement of all the scales comprising a second-order factor would ensure that information about progress in general problem areas are measured. Measuring all of the scales comprising a second-order factor prevents the loss of information that often results from practitioners' use of only a single scale to measure client progress.

The use of second-order factor analysis can assist social workers in understanding how client problems within given populations are related. This understanding of the relationships among client problems can be used in client assessments and can provide guidance in developing interventions that focus more fully on problem constellations rather than on a single, and often incomplete. diagnosis. Once client assessments are completed, second-order factor results can be used in documenting and collapsing the complex data of multi problem situations. This would result in more concise social work documentation that effectively reflects a person-environment focus in assessments and interventions.

Studies of higher-order factors related to the structure-of-intelligence have yielded important empirical information about the validity of hierarchical theoretical constructs of intelligence. Other studies have demonstrated how the higher-order factor structure-of-intelligence tests differ for clients believed to have deficits in cognitive-perceptual functioning. In social work, studies that examine higher-order factors of multidimensional functioning offer the potential of developing needed practice knowledge about the general problem constellations of different client populations and improving agency and clinical services provided to clients. Further research is needed on the second-order factor structures of the MPSI and other multidimensional scales that measure environmental, social, and individual functioning to develop more comprehensive information about clinical populations. Specifically, future studies should address the question of the extent to which a variety of clinical populations differ with regard to the second-order factor structures of multidimensional instruments used in social work to measure client progress. If differences in the second-order factor structures are found among various clinical populations, this information can be used to inform practitioners about those interventions having greater potential for success with a given clinical population. Research that examines the efficacy of practice interventions that are based on clinical hypotheses derived from the findings of second-order factors studies will benefit social work by generating 
knowledge about how to apply interventions with greater specificity to problem constellations rather than to single diagnoses.

[This space left blank intentionally.] 
Tables

Table 1

Scale Descriptive Statistics, Standard Errors of Measurement (SEM), and Coefficient Alphas for the Persian Gulf Sample

\begin{tabular}{|c|c|c|c|c|c|}
\hline MPSI ${ }^{\mathrm{a}}$ Subscale & Sample Size & Mean Score & $S D$ & Alpha & $S E M$ \\
\hline Depression & 1,529 & 42 & 13.54 & 0.90 & 4.26 \\
\hline Self-Esteem & 1,526 & 38 & 12.21 & 0.88 & 4.17 \\
\hline Partner Problems & 1,210 & 35 & 16.97 & 0.93 & 4.48 \\
\hline Sexual Discord & 1,176 & 30 & 14.84 & 0.91 & 4.46 \\
\hline Child Problems & 895 & 19 & 10.19 & 0.87 & 3.62 \\
\hline Mother Problems & 1,316 & 23 & 14.09 & 0.92 & 4.03 \\
\hline Father Problems & 1,073 & 22 & 16.12 & 0.93 & 4.23 \\
\hline Personal Stress & 1,528 & 44 & 17.19 & 0.95 & 3.88 \\
\hline Friend Problems & 1,450 & 26 & 13.89 & 0.93 & 3.66 \\
\hline Neighbor Problems & 1,046 & 41 & 17.23 & 0.92 & 4.89 \\
\hline School Problems & 545 & 28 & 10.06 & 0.86 & 3.70 \\
\hline Aggression & 1,524 & 28 & 12.45 & 0.88 & 4.34 \\
\hline Work Associates & 1,240 & 33 & 14.92 & 0.94 & 3.57 \\
\hline Family Problems & 1,510 & 33 & 17.33 & 0.95 & 3.82 \\
\hline Suicide & 1,523 & 13 & 12.33 & 0.97 & 2.13 \\
\hline Nonphysical Abuse & 1,190 & 17 & 13.78 & 0.91 & 4.11 \\
\hline Physical Abuse & 1,181 & 02 & 3.49 & 0.84 & 1.39 \\
\hline Fearfulness & 1,532 & 20 & 22.91 & 0.97 & 4.00 \\
\hline Ideas of Reference & 1,528 & 16 & 20.73 & 0.95 & 4.43 \\
\hline Phobias & 1,529 & 22 & 20.03 & 0.91 & 6.14 \\
\hline Guilt & 1,525 & 27 & 12.87 & 0.92 & 3.60 \\
\hline Work Problems & 1,174 & 26 & 9.25 & 0.79 & 4.21 \\
\hline Confused Thinking & 1,530 & 37 & 10.53 & 0.95 & 2.42 \\
\hline Disturbing Thoughts & 1,529 & 30 & 13.73 & 0.97 & 2.37 \\
\hline Memory Loss & 1,529 & 30 & 9.93 & 0.92 & 2.86 \\
\hline Alcohol Abuse & 1,492 & 15 & 15.59 & 0.94 & 3.86 \\
\hline Drug Abuse & 1,453 & 04 & 8.62 & 0.96 & 1.68 \\
\hline
\end{tabular}

a. MPSI = Multi-Problem Screening Inventory. 
Table 2

Principal Component/Promax Factor Structure Loadings (correlations) for Second-Order Factors Derived From the A Priory Primary Factors

\begin{tabular}{|c|c|c|c|}
\hline $\begin{array}{l}\text { Subscales Sorted by } \\
\text { Factor Loadings }\end{array}$ & Factor 1 & Factor 2 & Factor 3 \\
\hline \multicolumn{4}{|l|}{ Individual Dysfunction } \\
\hline Depression & 0.75500 & 0.64356 & 0.49709 \\
\hline Self-Esteem & 0.69556 & 0.68560 & 0.44989 \\
\hline Personal Stress & 0.80850 & 0.56371 & 0.40963 \\
\hline Aggression & 0.50680 & 0.33700 & 0.22693 \\
\hline Suicide & 0.68012 & 0.44099 & 0.36187 \\
\hline Fearfulness & 0.82636 & 0.38643 & 0.29535 \\
\hline Ideas of Reference & 0.73089 & 0.48205 & 0.41119 \\
\hline Phobias & 0.78295 & 0.38886 & 0.28075 \\
\hline Guilt & 0.76390 & 0.46249 & 0.37030 \\
\hline Confused Thinking & 0.83866 & 0.38136 & 0.23740 \\
\hline Disturbing Thoughts & 0.82773 & 0.35340 & 0.28319 \\
\hline Memory Loss & 0.71982 & 0.33443 & 0.18138 \\
\hline Alcohol Abuse & 0.34635 & 0.19104 & 0.32831 \\
\hline Drug Abuse & 0.21056 & 0.06561 & 0.20376 \\
\hline \multicolumn{4}{|c|}{ Family and Environmental Problems } \\
\hline Child Problems & 0.25992 & 0.52568 & 0.31763 \\
\hline Mother Problems & 0.25182 & 0.67408 & 0.25888 \\
\hline Father Problems & 0.24284 & 0.59212 & 0.15901 \\
\hline Friend Problems & 0.64263 & 0.68664 & 0.44433 \\
\hline Neighbor Problems & 0.44606 & 0.65554 & 0.29673 \\
\hline School Problems & 0.35989 & 0.49187 & 0.30911 \\
\hline Work Associates & 0.56534 & 0.69677 & 0.31512 \\
\hline Family Problems & 0.31859 & 0.77788 & 0.36970 \\
\hline Work Problems & 0.39955 & 0.57710 & 0.20682 \\
\hline \multicolumn{4}{|c|}{ Partner Relationship Problems } \\
\hline Partner Problems & 0.30331 & 0.43419 & 0.84963 \\
\hline Sexual Discord & 0.29405 & 0.40682 & 0.75866 \\
\hline Nonphysical Abuse & 0.34688 & 0.36602 & 0.83615 \\
\hline Physical Abuse & 0.25489 & 0.18991 & 0.55513 \\
\hline
\end{tabular}


Table 3

Principal Component/Promax Factor Pattern Loadings (standardized regression coefficients) for Second-Order Factors Derived from the A Priory Primary Factors

\begin{tabular}{|c|c|c|c|}
\hline $\begin{array}{l}\text { Subscales Sorted } \\
\text { by Factor Loadings }\end{array}$ & Factor 1 & Factor 2 & Factor 3 \\
\hline \multicolumn{4}{|l|}{ Individual Dysfunction } \\
\hline Depression & 0.54489 & 0.28266 & 0.15551 \\
\hline Self-Esteem & 0.44432 & 0.40883 & 0.08990 \\
\hline Personal Stress & 0.69634 & 0.16482 & 0.06393 \\
\hline Aggression & 0.45480 & 0.09188 & 0.00843 \\
\hline Suicide & 0.60268 & 0.07869 & 0.09224 \\
\hline Fearfulness & 0.86617 & -0.06936 & -0.00780 \\
\hline Ideas of Reference & 0.63662 & 0.08674 & 0.12470 \\
\hline Phobias & 0.80578 & -0.03070 & -0.01691 \\
\hline Guilt & 0.70751 & 0.05421 & 0.07141 \\
\hline Confused Thinking & 0.90226 & -0.05787 & -0.08503 \\
\hline Disturbing Thoughts & 0.89262 & -0.11605 & -0.00861 \\
\hline Memory Loss & 0.77565 & -0.02802 & -0.10585 \\
\hline Alcohol Abuse & 0.29107 & -0.08019 & 0.25273 \\
\hline Drug Abuse & 0.20845 & -0.12955 & 0.18298 \\
\hline \multicolumn{4}{|c|}{ Family and Environmental Problems } \\
\hline Child Problems & -0.04666 & 0.50269 & 0.10327 \\
\hline Mother Problems & -0.13877 & 0.76716 & -0.04212 \\
\hline Father Problems & -0.07287 & 0.69218 & -0.13282 \\
\hline Friend Problems & 0.36873 & 0.44722 & 0.09484 \\
\hline Neighbor Problems & 0.14357 & 0.59510 & -0.03399 \\
\hline School Problems & 0.12159 & 0.38949 & 0.08197 \\
\hline Work Associates & 0.28430 & 0.57383 & -0.06023 \\
\hline Family Problems & -0.13821 & 0.83375 & 0.03770 \\
\hline Work Problems & 0.15046 & 0.54513 & -0.10346 \\
\hline \multicolumn{4}{|c|}{ Partner Relationship Problems } \\
\hline Partner Problems & -0.06347 & 0.08097 & 0.83676 \\
\hline Sexual Discord & -0.03551 & 0.08716 & 0.73211 \\
\hline Nonphysical Abuse & 0.04685 & -0.04712 & 0.83981 \\
\hline Physical Abuse & 0.10083 & -0.12998 & 0.57621 \\
\hline
\end{tabular}




\section{References}

1. Bachelor, P. (1986). Higher-order factors in Guilford's SOI model: Divergent productions. Educational Research Quarterly, 11(2), 29-40.

2. Bachelor, P. (1989). Maximum likelihood confirmatory factor-analytic investigation of the factors within Guilford's structure-of-intellect model. Journal of Applied Psychology, 74, 797-803.

3. Bachelor, P., \& Bachelor, B. (1989). An investigation of the higher-order symbolic factors of cognition and convergent production within the structure of intellect model. Educational and Psychological Measurement, 49, 537-548.

4. Bachelor, P., \& Michael, W. B. (1991). Higher-order factors of creativity within Guilford's structure-of-intellect model: A re-analysis of a fifty-three variable data base. Creativity Research Journal, 4, 157-175.

5. Bachelor. P., Michael, W. B., \& Kim, S. (1994). First-order and higher-order semantic and figural factors in structure-of-intellect divergent production measures. Educational and Psychological Measurement, 54, 608-619.

6. Blaha, J., \& Mandes, E. (1993). The hierarchical factor structure of the WAIS-R for alcoholic adults. Journal of Clinical Psychology, 49, 740-745.

7. Blaha, J., Mandes, E., \& Swisher, C. W. (1987). The hierarchical factor structure of the WAIS-R for learning disabled adults. Journal of Clinical Psychology, 43, 280-286.

8. Blaha, J., \& Wallbrown, F. H. (1982). Hierarchical factor structure of the Wechsler Adult Intelligence Scale-Revised. Journal of Consulting and Clinical Psychology, 50, 652-660.

9. Cattell, R. B. (1966). The Scree Test for the number offactors. Multivariate Behavioral Research, 1, 245-276.

10. Cattell, R. B., \& Vogelman, S. (1977). A comprehensive trial of the Scree and KG criteria for determining the number of factors. Multivariate Behavioral Research, 12, 289-325.

11. Chen, Coy, \& Michael, W. B. (1993). Higher-order abilities conceptualized within Guilford's Structure-of-Intellect (SOI) model for a sample of United States Coast Guard Academy cadets: A re-analysis of an SOI data base. Educational and Psychological Measurement, 53, 941-950.

12. Chen, S. A., \& Michael, W. B. (1993). First-order and higher-order factors of creative social intelligence within Gilford's Structure-of-Intellect Model: A reanalysis of a Guilford data base. Educational and Psychological Measurement, 53, 619-641.

13. Gorsuch, R. L. (1983). Factor analysis (2nd ed.). Hillsdale, Nl: Lawrence Erlbaum.

14. Guilford, J. P. (1959). Three faces of intellect. American Psychologist, 14, 469-479.

15. Hepworth, D. H., \& Larsen, J. A. (1993). Direct social work practice: Theory and skills (4th ed.). Pacific Grove, CA: Brooks/Cole.

16. Hudson, W. W. (1990). The MPSI technical manual. Tallahassee, FL: WALMYR.

17. Hudson, W. w., \& McMurtry, S. L. (1997). Comprehensive assessment in social work practice: The Multi-Problem Screening Inventory. Research on Social Work Practice, 7, 79-98.

18. Michael, W. B., \& Bachelor, P. (1992). First-order and higher-order creative ability factors in structure-of-intellect measures administered to sixth-grade children. Educational and Psychological Measurement, 52, 261-273. 
19. Nunnally, J. C., \& Bernstein, I. (1994). Psychometric theory (3rd ed.). New York: McGraw-Hill. SAS Institute, Incorporated. (1989). SASISTAT user's guide, version 6 (4th ed.). Cary, NC: Author.

20. Sheafor, B. W., Horejsi, C. R., \& Horejsi, G. A. (1994). Techniques and guidelines for social work practice (3rd ed.). Boston: Allyn \& Bacon.

21. Tanaka, J. S., \& Huba, G. J. (1984). Confirmatory hierarchical factor analyses of psychological distress measures. Journal of Personality and Social Psychology, 46, 621-635.

22. Ulosevich, S. N., Michael, W. B., \& Bachelor, P. (1991). Higher-order factors in Structure-of Intellect (SOI) aptitude tests hypothesized to portray constructs of military leadership: A re-analysis of an SOI data base. Educational and Psychological Measurement, 51, 15-37.

23. Vernon, P. E. (1950). The structure of human abilities. New York: John Wiley.

24. Wallbrown, F. H., Elliott, C. D., McLoughlin, \& Blaha, J. (1984). The hierarchical factor structure of the British ability scales. Journal of Clinical Psychology, 40, 278-290.

25. Wilson, D., Sibanda, J., Sibanda, P., \& Wilson, C. (1989). Second-order factor structure of Cattell's High School Personality Questionnaire among Zimbabwean schoolboys. Journal of Social Psychology, 129, 419-420. 